2021, Volume 16, ATEE 2020 - Winter Conference. Teacher Education for Promoting WellBeing in School. Suceava, 2020, pages: 70-77/ https://doi.org/10.18662/lumproc/atee2020/05

\section{Using QR Codes as Compensatory Measure for Students with TSI}

\section{Robert BEREZOVSKI ${ }^{1}$ \\ Eugenia JIANU²}

${ }^{1}$ University lecturer. dr. University of Pitești, Romania

rberezovski@hotmail.com

${ }^{2}$ University lecturer. dr. University of Piteşti, Romania eugeniajianu@yahoo.ro
Abstract: In the context of new informational and communicative technologies (NTIC), the support for students with specific learning disabilities (TSI) should become increasingly easy to offer and implement. In accordance with the legal provisions of the methodological rules and their objectives, among the compensatory measures that can be offered to students with TSI during the teaching-learning process, is the use of computer / tablet with a software - vocal synthesizer, that turns the reading theme into a listening theme. In this category should also be included a smartphone with an application that allows reading the $Q R$ codes and that has the role of interpreting an image and decipher that code. The application can be downloaded from the App Store for Apple products) or from the Play Store (for Android). Taking into consideration that these codes allow a buge data storage due to the fact that the writing of data is done both vertically and horizontally, their use in the educational process takes on new dimensions. $Q R$ codes can be used in the teaching-learning process for students with dyslexia, simply by scanning the code with the mobile. Once generated, this code is applied on the manual or on teaching material for which it was generated and simply by scanning the code with the phone, the students can access the manual or teaching material in audio, video and text formats.

Keywords: specific learning disabilities; dyslexia; $Q R$ code.

How to cite: Berezovski, R., \& Jianu, E. (2021). Using QR Codes as Compensatory Measure for Students with TSI. In O. Clipa (vol. ed.), Lumen Proceedings: Vol. 16. ATEE 2020 Winter Conference. Teacher Education for Promoting Well-Being in School. Suceava, 2020 (pp. 70-77). Iasi, Romania: LUMEN Publishing House.

https://doi.org/10.18662/lumproc/atee2020/05 


\section{Introduction}

In the context of new informational and communicative technologies (NTIC), the support for students with specific learning disabilities (TSI) should become increasingly easy to offer and implement. Considering that these disabilities are not a consequence of a lack of learning opportunities, a lack of learning motivation, the result of an intellectual disability, of a limited intellect or of the existence of a sensory deficit (e.g. hearing, visual, motor) or of some affective and emotional psychiatric disorders or of autism spectrum disorders, of attention deficit and hyperactivity disorders and also are not the result of a form of brain trauma, the use of NTIC in the instructive-educational process can be a new tool for instructional adaptation.

Using NTIC should favor academic success of students through supporting didactic measures that guarantee adequate formation and promotes the development of each student found with deficiencies, during the process of acquiring learning abilities like riding, writing or basic arithmetic.

According to the methodological rules and their objectives, among the compensatory measures that can be provided for students with TSI in the teaching-learning process is the use of computer, laptop or tablet.

An effective tool for using NTIC in the teaching-learningassessment process, in addition to the smart devices mentioned above, is the new generation phones like smartphone, due to the applications that it is able to access, as well as their widespread use among students. Given the technological possibilities of smartphones due to the services they have, as well as the multitude of applications for mobile phones offered by different IT platforms, in our opinion, these tools should be used in teaching process on an increasing scale.

One of the numerous applications that can be downloaded on the phone and that can be helpful in the teaching process for students with TSI is the application that allows reading the QR codes (quick response), for example: QR Code Reader Scan. The new phone models have integrated the $\mathrm{QR}$ scanner into the camcorder, but you can also scan a $\mathrm{QR}$ online, for example, using www.qrstuff.com/scan.

The QR code was created in 1994 by the Japaneses from Denso Wave, Inc., a subsidiary corporation of Toyota. This application allows a quick and easy incorporation of a piece of information into a twodimensional bar code image that afterwards can be applied to various printed media. Although initially used to monitor auto components inside of 
production process, due to its specific characteristics the QR code quickly found its applicability in various fields such as advertising or media. Recently, these features are beginning to be harnessed in education, due to the fact that these QR codes can contain texts, audio files or URLs to different sites and they prove to be useful, especially in the sequences of fixating, consolidating and feedback, because they can be displayed on panels, they take up very little space and can contain a significant amount of easily accessible information. Once generated, this code is placed on the manual or teaching material in use and for which the code was generated.

In Estonia, the use of the QR Codes began 10 years ago, when "Digital Education" and computer programming were introduced at the $\mathrm{I}^{\text {st }}$ grade (Eram, 2018), and in India it will be printed, by the end of 2020, about 200 million manuals having a QR Code (Eram, 2018).

By downloading on the phone one of the applications that can read QR codes, from App Store (Apple) or Play Store (Android), and simply scanning a code, the students can access the manual, chapters from the manual or the just lessons, worksheets or other auxiliary teaching materials, in digital format (audio, video and text).

\section{Research questions/Aims of the research}

Since 2018 there is a web-site (www.manuale.gratis) that post manuals for subjects taught in I-VIII grades, which have associated a QR code. This QR code allows accessing the manuals as text. With the help of TTS applications - Text to Speech, the manuals are also accessed as audio, for example: www.manuale.gratis/07016-10, where 07016 represents the last 5 digits of the ISBN found on the last cover of the manual, and 10 is the number of the page.

\section{Research methods}

In order to confirm the reality of the statements related to the necessity to use NTIC, through the goodwill of the site administrator (axelsoft.net), we analyzed the data related to the persons who accessed the site, their place of origin, the type of device they used to access the manuals as well as the type of accessed manuals.

\section{Results}

Since 2018 till now, the number of visits increased exponentially, reaching in May 2020 to over 29.000 users that accessed approximately 60.000 pages, fig. no. 1 a) and b). 
Audience Overwiew

All Users

$100,00 \%$ page Views

30 Aug 2018 - 16 May 2020

Users

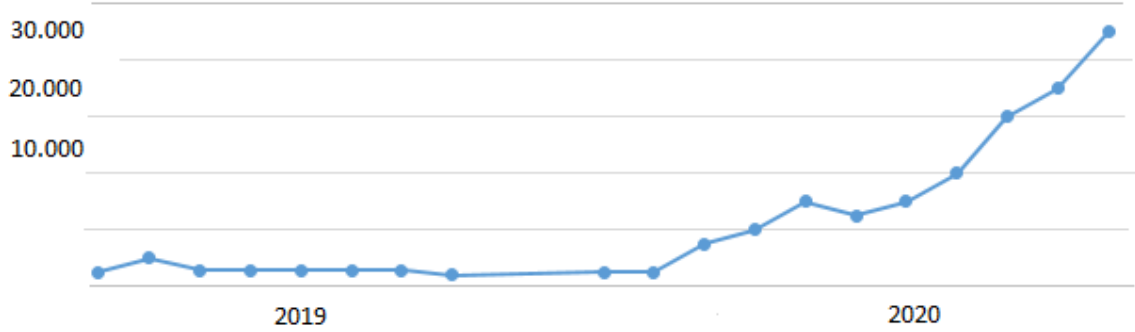

Fig. 1 a) Users number evolution

Source: Manuale Gratis, 2020

From analyzing the graphics from fig. no. 1 a) and b) it is noticeable a sudden increase in both number of visits and number of page accessed at one visit since 2020, increase probably also due to the coronavirus pandemic that led authorities to suspend classes for pre-school, primary, secondary, high school, vocational and post-secondary education, and to take the decision that these courses should be continued online, with the help of informational and communicative technologies.

Pages
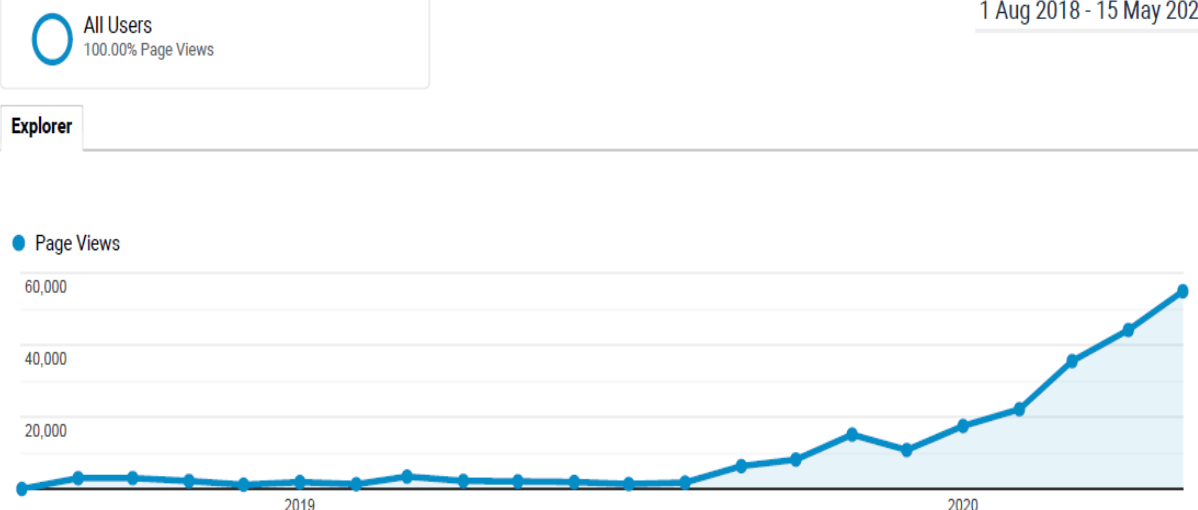

Fig.1 b). Evolution of the number of accessed pages.

Source: Manuale Gratis, 2020 
A number of 24.451 visits are from Romania and the rest of visits being from Moldavia, United States etc, fig. no. 2.

\begin{tabular}{llrl}
\multicolumn{2}{c}{ Country } & Users $\%$ Users \\
\hline 1. & Romania & 24,451 & $82.70 \%$ \\
\hline 2. & Moldova & 1,855 & $6.27 \%$ \\
\hline 3. & United States & 872 | $2.95 \%$ \\
\hline 4. & South Korea & $492 \mid 1.66 \%$ \\
\hline 5. & China & $296 \mid 1.00 \%$ \\
\hline 6. & Germany & $217 \mid 0.73 \%$ \\
\hline 7. & United Kingdom & $173 \mid 0.59 \%$ \\
\hline 8. & Japan & $146 \mid 0.49 \%$ \\
\hline 9. & Italy & $141 \mid 0.48 \%$ \\
\hline 10. & France & $77 \mid 0.26 \%$ \\
\hline
\end{tabular}

Fig. 2 User number distribution

Source: Manuale Gratis, 2020

The distribution of the 24.451 visits from Romania, for districts, can be observed in fig. no. 3 .

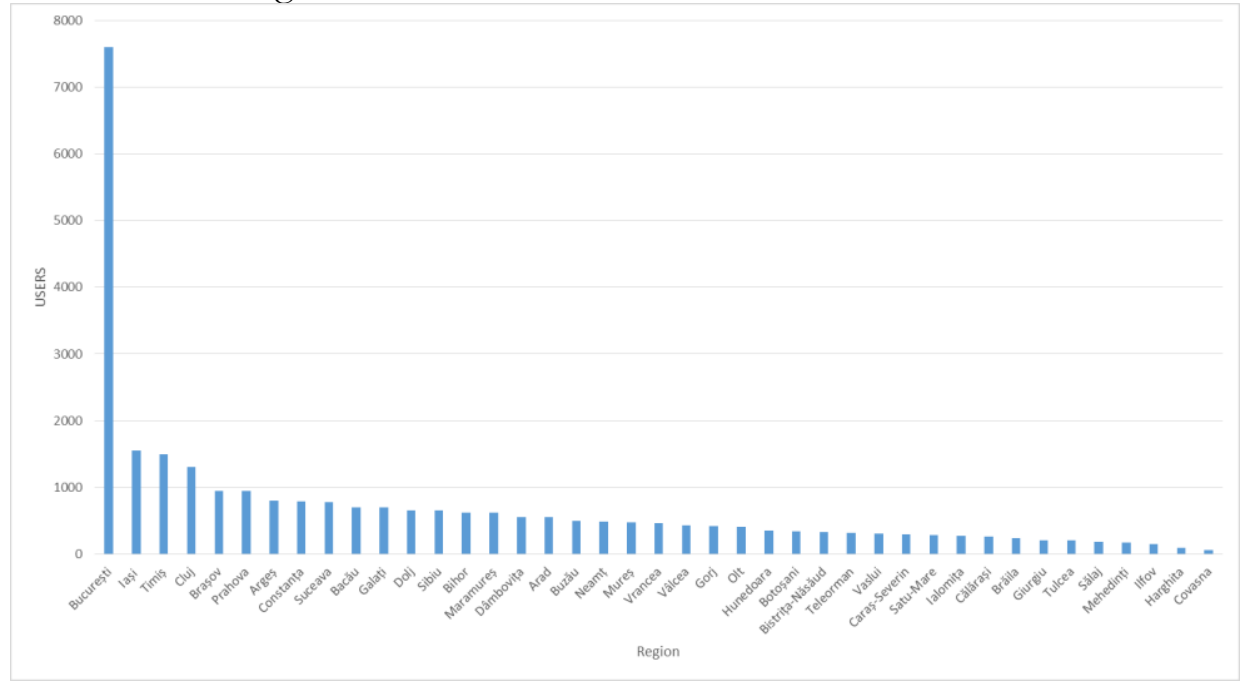

Fig. 3 Users number distribution by districts.

Source: Manuale Gratis, 2020

From a total of 29.332 visits, a number of 15.906 visits were made from a computer and 679 from a tablet (fig. no. 4). 


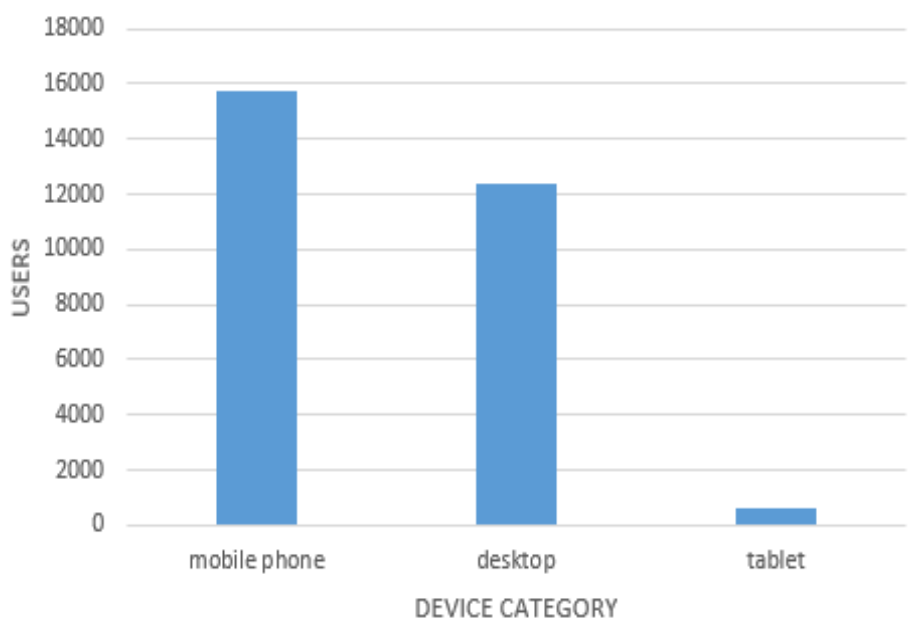

Fig.4 Users number distribution by the login device.

Source: Manuale Gratis, 2020

The most used electronic device used for accessing manuals is the mobile. In our opinion, this reality must be taken into consideration for utilizing NTIC into the instructional - educational process.

The most accessed manuals were those of physics, mathematics, biology, technological education, computer science (fig. 5).

Views (\%)

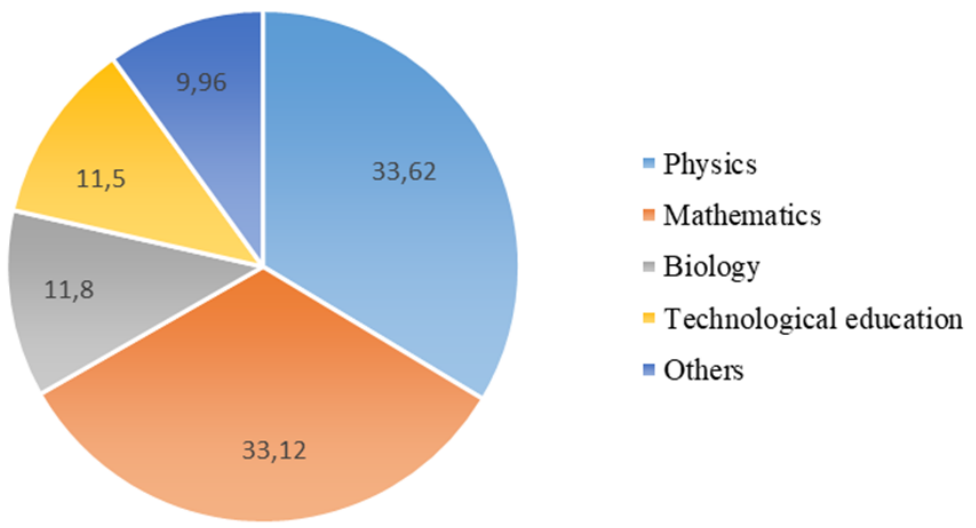

Fig.5 The distribution of accessed manuals.

Source: Manuale Gratis, 2020 


\section{Conclusions}

In this context, where there is an increasingly pronounced change in the approach of didactic processes from being teacher-centered to be student-centered, in the sense of placing the student at the center of the instructional-educational process and not the taught curriculum, we consider that the use of QR codes can provide opportunities for students to interact quickly and easily with a variety of content.

In differentiated schooling, students should have access to tools and teaching materials that stimulate their creativity, help them to discover and to develop their skills.

Using QR codes could be a way for students to more quickly and creatively understand the content taught in a lesson or it could be a tool for helping them gathering background information before starting a new learning unit. The differentiation should happen for students who approach and exceed the benchmarks at the class level as well as for students with special needs, as I said earlier.

The use of QR codes may complement the conventional teaching activities, adding plus value in terms of facilitating students' understanding of content, increasing motivation to learn, school activity, integration with nonformal educational activities, as well as in terms of design and development of lessons by the teacher, favoring differentiated training activities, a better coordination of didactic, collaborative and creative activities, thus being student-centered.

These applications and sites can also be used in the instructional process of students with TSI, who, by simply scanning the QR code with their mobile, will be able to access the didactic material.

I believe that the use of the QR code, as a compensatory measure offered for students with TSI, will lead toward the development of new curricular adaptation strategies focused on the student's needs, strategies that will allow him to compensate, from a functional point of view, the deficiencies caused by the presence of specific learning disabilities.

We also believe that the use of smartphones in the teaching-learningassessment process should not be reduced only to students with disorders or specific learning problems.

Although the use of $\mathrm{QR}$ code reading applications in Romanian education is at the beginning, we believe that the modern style of teachinglearning-assessment imposed in the didactic scenario will lead to stimulate participants' interest, causing them to be more active and involved in their own training. 
The use of the mobile allows the diversification of the didactic strategy, facilitating the students' access to information presented, in different ways: video and audio, more ample, more logically organized and variously structured.

We believe that for the new generations of students, accustomed to the avalanche of multimedia information and who have access to the latest generations of smart devices, the concept of assisting the educational process with the mobile is an intrinsic requirement.

For supporting of the above, we suggest to watch the following video clip which shows the way how the $\mathrm{QR}$ application is used, made at a school in Bucharest. All you have to do is scan the QR code below (Chiru, 2019):

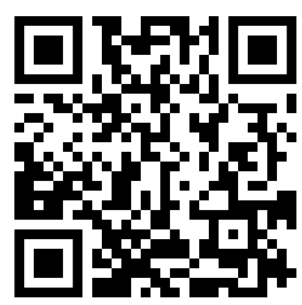

\section{References}

Eram, A. (2018). Learning Becomes Fun: Soon, QR Codes to 'Energise' Textbooks. News 18. https://www.news18.com/news/india/learning-becomes-funsoon-qr-codes-to-energise-textbooks-1759623.html.

Chiru, C. (2019, April 2). Joc cu QR Code Reader \& Claudia Chiru. [Video]. YouTube.

https://www.youtube.com/watch?v=a9PWFITVqGk\&feature=youtu.be

Manuale Gratis. (2020). http://manual.digital/may2020 